\title{
Unexplained Variance in Hydration Study
}

\author{
Colleen X. Muñoz ${ }^{1}$ and Michael Wininger ${ }^{2,3,4, *}$ \\ Department of Health Sciences and Nursing, University of Hartford, West Hartford, CT 06117, USA \\ Department of Rehabilitation Sciences, University of Hartford, West Hartford, CT 06117, USA \\ Department of Biostatistics, Yale University, New Haven, CT 06510, USA \\ 4 Cooperative Studies Program, Department of Veterans Affairs, West Haven, CT 06516, USA \\ * Correspondence: wininger@hartford.edu; Tel.: +1-860-768-5787
}

Received: 4 June 2019; Accepted: 30 July 2019; Published: 7 August 2019

check for updates

\begin{abstract}
With the collection of water-intake data, the National Health and Nutrition Examination Survey (NHANES) is becoming an increasingly popular resource for large-scale inquiry into human hydration. However, are we leveraging this resource properly? We sought to identify the opportunities and limitations inherent in hydration-related inquiry within a commonly studied database of hydration and nutrition. We also sought to critically review models published from this dataset. We reproduced two models published from the NHANES dataset, assessing the goodness of fit through conventional means (proportion of variance, $\mathrm{R}^{2}$ ). We also assessed model sensitivity to parameter configuration. Models published from the NHANES dataset typically yielded a very low goodness of fit $\mathrm{R}^{2}<0.15$. A reconfiguration of variables did not substantially improve model fit, and the goodness of fit of models published from the NHANES dataset may be low. Database-driven inquiry into human hydration requires the complete reporting of model diagnostics in order to fully contextualize findings. There are several emergent opportunities to potentially increase the proportion of explained variance in the NHANES dataset, including novel biomarkers, capturing situational variables (meteorology, for example), and consensus practices for adjustment of co-variates.
\end{abstract}

Keywords: hydration; water intake; obesity; modeling; database; NHANES; chronic disease; big data

\section{Introduction}

Water intake and hydration status are evolving as increasingly important points of focus in far-reaching corners of medicine and public health. Investigators in search of phenotypic risk factors and as a possible strategy for mitigating disease burden and progression have targeted total water intake practices in myriad diseases including hyperglycemia [1,2], obesity [3-8], diabetes mellitus [5,6,9-12], metabolic syndrome [6,13], cardiovascular diseases [14-18], chronic kidney disease [5,19-23], cystic renal disease [24-26], and bladder cancer [27-29]. Given the extensive foundational research linking total water intake to other high-relevance morbidities, it is exciting that the National Center for Health Statistics collects water intake data. However, are we leveraging this resource optimally?

In this article, we explore model design in database-supported hydration inquiry. We contrast model diagnostics and explore optimization scenarios by reproducing two recently published regression models related to hydration. In particular, we look into regression models in hydration, published by others, by way of the model goodness of fit parameter, the $R^{2}$. The coefficient of determination $\left(0 \leq R^{2}\right.$ $\leq 1)$ is a standard measure for how well scatter data fit to their model regressor; it is the proportion of explained variation relative to total variation. A low $R^{2}$ value indicates a large proportion of unexplained variance; a high $\mathrm{R}^{2}$ indicates that much of the variance observed in the data are explained by effects described in the model.

Our interest was to replicate two recently-published models in order to ascertain their goodness of fit. We also wanted to extend these published works by assessing the sensitivity of the model goodness 
to parameter selection. The models studied here are mutually similar but distinct, making use of different variables in both prediction and response, but both had a similar design in that regression models were designed to test specific hypotheses within a large, publicly available dataset. Our objective was to critically review the state of the art-and identify opportunities to enhance-database-driven inquiry into human hydration.

\section{Methods and Results}

\subsection{Study Selection}

We took as exemplars two recently published papers: Rosinger et al. [3] and Chang et al. [4]. Both groups leveraged the same dataset (National Health and Nutrition Examination Survey (NHANES) 2009-2012), tested for associations between hydration and body composition, were posed as population studies (i.e., weighted analyses), and utilized a parallel design, i.e., tandem linear and logistic regression. Naturally, these papers differ in terms of co-variate selection, dataset filtering, the selection of predictor versus response variable, and the age-adjustment of hydration status. Full methodologies are described in the original manuscripts, but in short summary: The Rosinger et al. study $(n=9528)$ utilized urine osmolality (URXOAV) as the response variable, with the following predictor variables: Age (RIDAGEYR) stratified 20-39, 40-59, and $\geq 60$ years; gender (RIAGENDR); race-ethnicity (RIDRETH1) re-coded into three groups (Non-Hispanic White, Non-Hispanic Black, and Hispanic); fasting session index (PHDSESN); physical activity (MINMODVIG) as low versus high-activity at 150 min of moderate or vigorous activity per week; caffeine intake (DR1TCAFF), stratified as low versus high-intake at $400 \mathrm{mg}$; alcohol consumed (DR1TALCO), total calories consumed (DR1TKCAL); diabetes status (DIQ010); and moisture-intake (DR1TMOIS) stratified at males $<3700 \mathrm{~g}$, females $<2700 \mathrm{~g}$, or lactating females $<3800 \mathrm{~g}$. The Chang et al. study $(n=9601)$ utilized BMI (BMXBMI) as a response variable, with urine osmolality, gender, race-ethnicity, the ratio of family income to poverty level (INDFMPIR), and age as continuous variables. Data were obtained de novo from the NHANES repository at CDC.gov. These studies were selected because they provided the right balance between comparability and mutual novelty, both had already been cited multiple times in their short history in print, and both papers were written in a way that facilitated replication.

\subsection{Model Diagnostics}

A detail not reported in either study was a model goodness of fit. We extracted the model fit as $\mathrm{R}^{2}$ values, defined as 1 minus the ratio of residual deviance to null deviance. Our motivation for reporting $\mathrm{R}^{2}$ is that this is an exquisitely important parameter used to contextualize analytical models. Both papers (Chang et al. and Rosinger et al.) presented significance values ( $p$-values) for individual parameters, and these values are informative as to the existence of a relationship between two variables. However, neither paper reported a goodness of fit $\left(\mathrm{R}^{2}\right)$, so there was no way to draw an inference as to which group presented a more compelling model, or whether either model was tenable at all. A further review of models in this area of study revealed that it is the rare exception that a model goodness is published alongside the model results. Thus, there is an opportunity to provide valuable supporting information regarding our analytical approaches in the analysis of hydration datasets.

In total, eight models were considered: Two from Chang et al. and six from Rosinger et al. $\mathrm{R}^{2}$ was low, ranging from 0.03 to 0.11 . The models shown here reflect an extension of the original published analyses, starting with a reproduction of the models as originally published, using identical datasets and identical assumptions. We considered our replication successful when we were able to reproduce all linear regression coefficients described in Chang et al. to within $1 \%$ of their printed value, and we were able to reproduce all linear regression coefficients in the normal-weight dataset described in Rosinger et al., also to within $1 \%$. Once we were able to confidently replicate these published findings by others, thus confirming their models as described, we felt comfortable extending their models. As an illustration, consider the univariate regressions shown in Figure 1. Both models yield a statistically 
significant relationship between predictor and response variables (both $p$-values were incalculably small, below the precision of the computer), but neither had an $\mathrm{R}^{2}$ above $2.5 \%$.
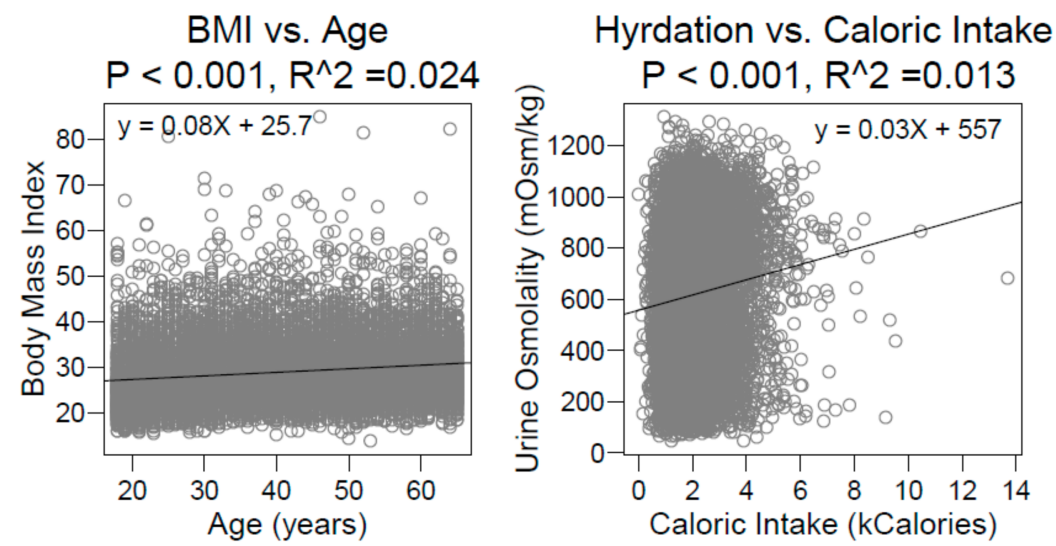

Figure 1. Univariate regressions from the National Health and Nutrition Examination Survey (NHANES) 2009-2010 and 2011-2012 datasets, based on Chang et al. (Left) and Rosinger et al. (Right). Both regressions have highly significant $p$-values but negligible $\mathrm{R}^{2}$.

We note that the relationships demonstrated in these plots depart somewhat from those reported in the prior studies due to their use of multi-variate models and weighted regressions. We have shown unweighted univariate models for the sake of clarity in visualization. Nevertheless, these figures are useful as visual aids in demonstrating the low goodness of fit in these studies. Could the weakness of these models be explained by variable configuration? We tested this in three different variables.

\subsection{Urine Osmolality and BMI}

Rosinger et al. posed hydration (via urine osmolality) as a response variable adjusted for age via the linear transformation $831 \mathrm{mOsm} / \mathrm{kg}-3.4 \times$ (age -20 years), per published guidance [30,31], and BMI as a trichotomous predictor: Normal, overweight, and obese (BMI <25, 25-30, and $\geq 30$ ). Chang et al. posed hydration as a predictor variable without adjusting for age, and they treated body composition as a dichotomous quantity: Normal versus obese stratified at BMI $\geq 30$.

In order to test model sensitivity to variable configuration, we assessed the goodness of fit on the published regression models with four different settings: Hydration status with and without age adjustment and BMI as a continuous versus categorical variable. For these four models, the threshold for adequate hydration was systematically altered over a range of urine osmolality values from 200 to $1100 \mathrm{mOsm} / \mathrm{kg}$. Thus, eight models were tested in total: Four variants from Chang et al. and four from Rosinger et al.; the BMI as a continuous versus factor variable and hydration as an adjusted versus unadjusted variable.

We found that there were substantial differences in model fit depending on the defined threshold for adequate hydration status and that this relationship was opposite between the papers $\left(\mathrm{R}^{2}\right.$ maximized at extreme thresholds in models derived from Rosinger et al. versus optimization in mid-range values in models derived from Chang et al.). We also noted that age adjustment seemed to have had a profound impact on the Rosinger models but not on Chang's models-vice-versa for BMI as a continuous versus categorical measure (Figure 2). While not rigorously assessed, we suspect that this is most likely due to their respective positioning as outcome measures, as opposed to differences in datasets or inclusion of other co-variates.

A few remarks bear discussion regarding our methodology and interpretation. Firstly, Rosinger implemented separate models for each category. Here, we merged all data together and included BMI as a co-variate. While this changes the nature of the model, perturbing a single model facilitates interpretation versus three separate models, it allows for a direct contrast against Chang's results. 
We specifically decided not to alter the stratification of BMI (Chang: Two-level; Rosinger: Three-level), as we felt it was valuable to retain this semblance of the published model. Additionally, we note that we intentionally tested urine osmolality ranges that were physiologically unrealistic: Stratifying at $200 \mathrm{mOsm} / \mathrm{kg}$ and $1100 \mathrm{mOsm} / \mathrm{kg}$ is unknown in the literature. While we were interested in a narrower range of strata (threshold 500-800 mOsm/ $\mathrm{kg}$ ), we felt it appropriate to test for model behavior beyond those benchmarks in order to fully describe the relationship between the model and its parameter configuration.
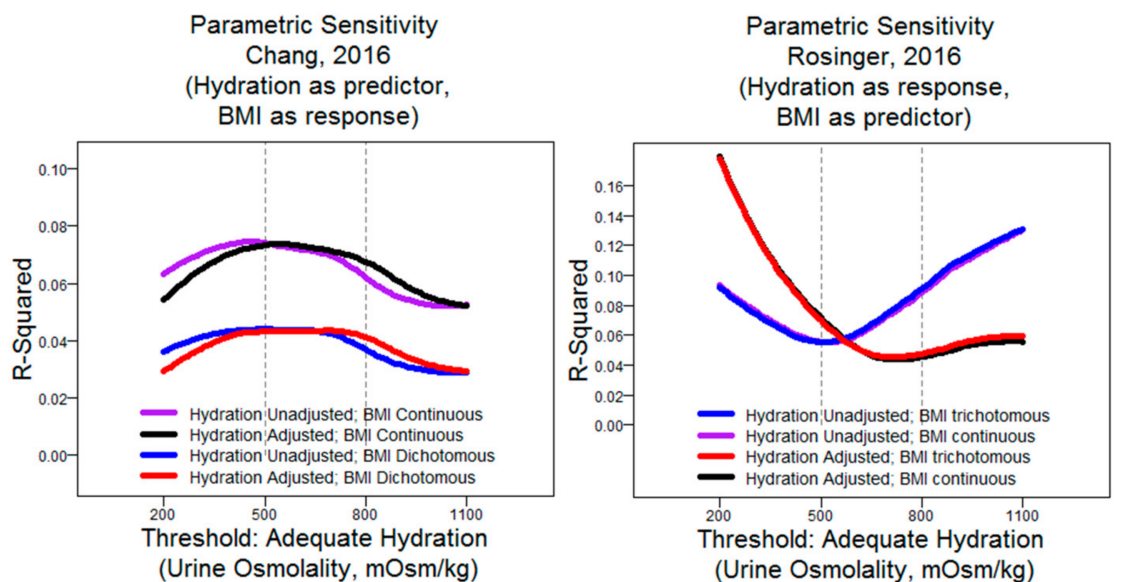

Figure 2. Model goodness $\left(\mathrm{R}^{2}\right)$ versus hydration threshold (via urine osmolality) in sensitivity analysis of two database studies on hydration in relation to body composition.

While it is certainly more common to consider hydration to be adequate at more moderate ranges of urine osmolality, we note that there are some respondents with values as or more extreme than this range (approximately 6\% of respondents were below $200 \mathrm{mOsm} / \mathrm{kg}$, and approximately $2 \%$ of respondents were above $1100 \mathrm{mOsm} / \mathrm{kg}$ ), so while such extreme boundaries are unlikely to be useful in stratifying the general population, they are physiologically meaningful and might conceivably be of interest to those making inquiries about extreme hydration status levels. Our interest in such extreme thresholds was to explore the edge effects of the relationship between dichotomized hydration status and model goodness in order to verify that model performance is spectral and to provide perspective as to the impact of threshold selection outside of the historical range.

Lastly, we observed that the model fits were generally very weak: $R^{2} \leq 0.10$ in all models in the interval between 500 and $800 \mathrm{mOsm} / \mathrm{kg}$ of urine osmolality. Separately, we assessed whether model fit would improve with urine osmolality as a continuous variable, and we found that the results were similar: $0.10 \leq \mathrm{R}^{2} \leq 0.12$ in all simulations of Rosinger's models and $0.05 \leq \mathrm{R}^{2} \leq 0.08$ in Chang's models (Figure 3).

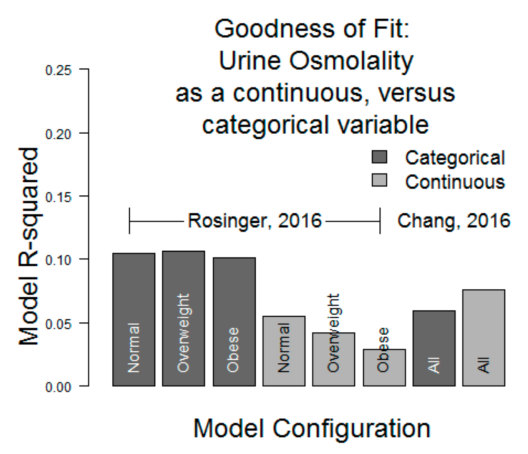

Figure 3. Model goodness $\left(\mathrm{R}^{2}\right)$ comparison, incorporating hydration as a continuous variable versus categorical variable $\mathrm{R}^{2}<0.12$ in all models. 


\subsection{Water Intake}

Rosinger's work categorizes respondents according to their water intake, with a two-level stratification, also accounting for sex (and within females: Lactation status). We tested other stratification approaches in order to test the sensitivity of the model to this parameter (Table 1).

Table 1. Goodness of fit of Rosinger et al. with various water intake stratifications used in previous publications. Cells contain $\mathrm{R}^{2}$ values obtained from regression models built from the published model. Top row is the replicated model from Rosinger et al.; all other rows use same dataset and same model as Rosinger et al., but with the altered stratification of a single variable (water intake). Some stratifications showed an improved goodness of fit $\left(\mathrm{R}^{2}\right.$ greater than Rosinger et al.); some stratifications showed a degraded goodness of fit ( $R^{2}$ less than Rosinger et al.). All models showed a generally weak model fit $\left(\mathrm{R}^{2}<0.15\right)$.

\begin{tabular}{lccccc}
\hline & Norm. & OWt & Obese & All & Strata (Water Intake (mL/day)) \\
\hline Rosinger, 2016 [3] & 0.111 & 0.110 & 0.107 & 0.095 & $<2700(\mathrm{~F}),<3700(\mathrm{M}),<3800($ Lactating F) \\
Armstrong, 2012 [32] & 0.132 & 0.109 & 0.114 & 0.101 & $\{0,1507,1745,2109,2507,2945,3407, \infty\}$ \\
Armstrong, 2010 [33] & 0.132 & 0.110 & 0.113 & 0.100 & $\{0,1382,2008,2048,2453,2614,3261, \infty\}$ \\
Johnson, 2015 [34] & 0.127 & 0.108 & 0.107 & 0.099 & $\{0,1620,3210, \infty\}$ \\
Muñoz, 2015 [35] & 0.126 & 0.106 & 0.111 & 0.099 & $\{0,1500,2250,3130, \infty\}$ \\
Sontrop, 2013 [19] & 0.114 & 0.109 & 0.112 & 0.097 & $\{0,2000,4300\}$ \\
Pross, 2014 [36] & 0.101 & 0.095 & 0.093 & 0.084 & $\{0,1200,2000, \infty\}$ \\
Perrier, 2013 [37,38] & 0.107 & 0.099 & 0.103 & 0.080 & $\{0,1200 ; 2000,4000\}\}^{1}$ \\
Roussel, 2011 [1] & 0.080 & 0.086 & 0.094 & 0.077 & $\{0,500,1000, \infty\}$ \\
\hline
\end{tabular}

Norm = Normal Weight; OWt $=$ Overweight. Strata defined or inspired by recent studies in hydration inquiry.

${ }^{1}$ Middle hydration group (1200-2000 mL/d) and extremely hydrated (>4000 mL/d) censored.

Results were mixed: Some stratification designs yielded improved fits in the linear regressions based on Rosinger's model, while some designs yielded a weaker fit. We note that even the best model among the 32 created yielded $\mathrm{R}^{2}<0.14$.

\section{Discussion}

\subsection{Modeling}

The papers analyzed here are not atypical in not having reported their $\mathrm{R}^{2}$ : We are unaware of any prior database studies in hydration where model fit is reported. However, they highlight the problematic emphasis of a significance test over a heuristic and more reflective of model goodness of fit [39]. The $p$-value does not provide information about whether the data are especially adherent to the regressor. The $p$-value indicates the relationship's existence, and $\mathrm{R}^{2}$ indicates the relationship's precision.

Moreover, each point of inquiry will require its own assumptions and its own selection of response variables or outcome measures, co-variates, and data conditioning steps. It is not possible for this manuscript to serve as guidance for model design, and it is beyond the scope of this paper to critically review the designs adopted by others. Rather, we recognize the inherent variation in analytical approaches that have been published to date and that there is further variety to come. We do strongly encourage thoroughness in explaining variable selection, assumption declarations, and in reporting model goodness.

Regression models in the study of hydration face a substantial design challenge: Complex co-variate interdependencies. Total body water balance is a function of water gains (via beverages, foods and metabolic water) and losses (via sweat, urine, feces and respiratory losses). Those who expect these factors to be highly co-dependent will argue that a model containing multiple factors among this set to be poorly-posed for its inclusion of collinearities [40-42]. At the other extreme, those who view these factors to be acceptably independent will argue that database studies are unviable for their lack 
of collection of the many meaningful determinants of body water balance and that those few that are present will be inadequately supported and "over-interpreted" [43-46].

\subsection{Asynchrony}

The NHANES survey incorporates a variety of reporting windows. Dietary recall estimates consumption during the 24-h period prior to the examination center visit (midnight to midnight); physical activity reports incorporate the past seven days, past 30 days, and "in a typical week," which may synchronize poorly with the timing of dietary information; and urine samples are collected on the day of the examination center visit, where participants are randomly assigned to appointments in the morning, afternoon, or evening, which vary somewhat versus protocols for optimal hydration assessment [38] and canonical renal function testing [47]. Investigators may or may not find this sequence (survey, delay, then measure) serviceable; others may not recognize that these are not contemporaneous measurements and may mis-interpret the models altogether.

\subsection{Biomarkers}

Tools used to indicate hydration process and status have been disputed, and no gold standard currently exists for an appropriate assessment across all scenarios [31,48,49]. While elevated urine osmolality has much perceived utility as a hydration biomarker [34,37,50,51], some question its validity with single (spot) samples [52,53]. Urine osmolality has noteworthy interindividual variation $[38,53]$ and is an ephemeral data point which measures hydration status in an instantaneous way. However, diet, physical activity, and phenotype are more enduring. Thus, there is great need for novel biomarkers to capture this hysteresis. One emergent marker, an arginine vasopressin (AVP) surrogate, copeptin, has shown preliminary promise as a water-balance indicator with robustness to various levels of hydration status and attenuation following an increased water intake intervention [54]. Copeptin has high molecular stability compared to AVP that aids in more accurate and less complicated measurement [55], and AVP and copeptin can distinguish acute and chronic water consumption variations [37,56], rendering this circulating protein a potentially attractive option to better characterize participants' water intake practices. While it is likely that there is no single substance or indicator with optimal responsiveness to daily hydration status [32], there is reason to continue searching for biomarkers with increasing fidelity to hydration status, as there is currently an unknown proportion of unexplained variance attributable to the biomarkers available currently.

\subsection{Weather}

NHANES currently does not collect information related to weather conditions at the time of data collection [57-60]. Seasonality corrections are common [32,61-64], although they are not universally justified [65,66], perhaps because of the complexity in adjusting for such a diffuse variable [67]. It would be feasible to document local weather conditions at or near to the time of survey response; this could be designed to capture weather in locales where the respondent habited in the preceding $24 \mathrm{~h}$ or to capture specific exposures, e.g., "Did you spend most of your time in a climate-controlled building or outdoors?" We observe that accounting for weather is not necessarily the sole province of future NHANES iterations: It is strictly possible to obtain zip-level geographic identifiers and date-of-survey information from restricted data (research data center) which could be cross-referenced against a historical weather database, although this requires some assumptions about a lack of travel.

\subsection{Analytic Approach}

Clearly, relationships between variables are labile to the way each variable is posed, and there are unlimited ways to create an analytical model. Should water intake be adjusted according to body composition, daily max ambient temperature, Mean temperature, or a composite measure accounting for time spent outdoors, total amount of direct sunlight, temperature and wind speed? Wearable sensors capable of recording climatic parameters are becoming increasingly prevalent [68-71], 
and perhaps large population investigations will soon have access to more accurate estimations of internal body temperature [72,73], sweat rate [74], and physical activity due to an increasingly robust infrastructure to support analysis of pedometers [75]. Furthermore, we recommend reporting the model goodness of fit as is conventional in modeling [76-78]. There are, as of yet, no published $\mathrm{R}^{2}$ values for hydration models in public datasets; without knowing where our benchmarks lie, it is impossible to know whether our models are keeping pace with the field in terms of explained variance. Where these actions are practicable, investigators should make efforts to incorporate them; where these actions are inappropriate, researchers should justify their approach.

\section{Conclusions}

With continued investigation into hydration practices and health outcomes, optimal model design, statistical reporting, and database extensions are warranted. By manipulating two recently-published hydration models, we were able to show (1) a substantial variation in the model fit depending on parameter configurations and (2) a consistently weak model fit, i.e., $\mathrm{R}^{2}<0.14$. We propose the inclusion of variables contributing to body water balance, which might increase the proportion of explained variance in a hydration study and mitigate artificial associations. In addition, consensus variable selection and stratification will increase comparability between studies. We make the following additional suggestions regarding targets for the advancement of the science and communication of results within the study of hydration: (1) The aggressive pursuit of promising biomarkers such as copeptin; (2) the creative utilization of assistive resources like meteorological databases; (3) the integration of advanced biostatistical techniques such as principal components analysis, survival analysis, time-series and longitudinal analysis; and (4) the detailed reporting of model goodness in any paper where modeling is employed. In particular, we recommend $R^{2}$ and not merely a model's $p$-value, as statistical significance is not nearly as informative as proportion of variance explained. Through the establishment of best practices and identification of new opportunities in hydration study, we anticipate that the maximum value can be obtained from database-driven inquiry, both past and future.

Author Contributions: Designed Research, C.X.M. and M.W.; conducted Research, C.X.M. and M.W.; data analysis and statistical analysis, M.W.; writing, C.X.M. and M.W.; responsibility for final content, C.X.M. and M.W.

Funding: Work was supported by internal grant from the College of Education, Nursing and Health Professions; University of Hartford.

Conflicts of Interest: The authors have no personal, professional, or financial relationships that might influence this work.

Ethics Statement: The procedures followed were in accordance with the ethical standards of the institution or regional committee on human experimentation and that approval was obtained from the relevant committee on human subjects and/or animal welfare.

\begin{tabular}{ll}
\multicolumn{2}{l}{ Abbreviations } \\
AVP & Arginine vasopressin \\
BMI & Body-mass index \\
$\mathrm{d}$ & Day \\
$\mathrm{kg}$ & Kilogram \\
$\mathrm{mL}$ & Milliliter \\
$\mathrm{mOsm}$ & Milliosmoles \\
NHANES & National Health and Nutrition Examination Survey \\
OWt & Overweight
\end{tabular}

\section{References}

1. Roussel, R.; Fezeu, L.; Bouby, N.; Balkau, B.; Lantieri, O.; Alhenc-Gelas, F.; Marre, M.; Bankir, L. Low water intake and risk for new-onset hyperglycemia. Diabetes Care 2011, 34, 2551-2554. [CrossRef] [PubMed] 
2. Taveau, C.; Chollet, C.; Waeckel, L.; Desposito, D.; Bichet, D.G.; Arthus, M.F.; Magnan, C.; Philippe, E.; Paradis, V.; Foufelle, F.; et al. Vasopressin and hydration play a major role in the development of glucose intolerance and hepatic steatosis in obese rats. Diabetologia 2015, 58, 1081-1090. [CrossRef]

3. Rosinger, A.Y.; Lawman, H.G.; Akinbami, L.J.; Ogden, C.L. The role of obesity in the relation between total water intake and urine osmolality in US adults, 2009-2012. Am. J. Clin. Nutr. 2016, 104, 1554-1561. [CrossRef] [PubMed]

4. Chang, T.; Ravi, N.; Plegue, M.A.; Sonneville, K.R.; Davis, M.M. Inadequate Hydration, BMI, and Obesity Among US Adults: NHANES 2009-2012. Ann. Fam. Med. 2016, 14, 320-324. [CrossRef]

5. Tasevska, I.; Enhorning, S.; Christensson, A.; Persson, M.; Nilsson, P.M.; Melander, O. Increased Levels of Copeptin, a Surrogate Marker of Arginine Vasopressin, Are Associated with an Increased Risk of Chronic Kidney Disease in a General Population. Am. J. Nephrol. 2016, 44, 22-28. [CrossRef] [PubMed]

6. Enhorning, S.; Bankir, L.; Bouby, N.; Struck, J.; Hedblad, B.; Persson, M.; Morgenthaler, N.G.; Nilsson, P.M.; Melander, O. Copeptin, a marker of vasopressin, in abdominal obesity, diabetes and microalbuminuria: The prospective Malmo Diet and Cancer Study cardiovascular cohort. Int. J. Obes. (2005) 2013, 37, 598-603. [CrossRef]

7. Dennis, E.A.; Dengo, A.L.; Comber, D.L.; Flack, K.D.; Savla, J.; Davy, K.P.; Davy, B.M. Water consumption increases weight loss during a hypocaloric diet intervention in middle-aged and older adults. Obesity 2010, 18, 300-307. [CrossRef]

8. Stookey, J.D.; Constant, F.; Popkin, B.M.; Gardner, C.D. Drinking water is associated with weight loss in overweight dieting women independent of diet and activity. Obesity 2008, 16, 2481-2488. [CrossRef]

9. Enhorning, S.; Wang, T.J.; Nilsson, P.M.; Almgren, P.; Hedblad, B.; Berglund, G.; Struck, J.; Morgenthaler, N.G.; Bergmann, A.; Lindholm, E.; et al. Plasma copeptin and the risk of diabetes mellitus. Circulation 2010, 121, 2102-2108. [CrossRef]

10. Abbasi, A.; Corpeleijn, E.; Meijer, E.; Postmus, D.; Gansevoort, R.T.; Gans, R.O.; Struck, J.; Hillege, H.L.; Stolk, R.P.; Navis, G.; et al. Sex differences in the association between plasma copeptin and incident type 2 diabetes: The Prevention of Renal and Vascular Endstage Disease (PREVEND) study. Diabetologia 2012, 55, 1963-1970. [CrossRef]

11. Wannamethee, S.G.; Welsh, P.; Papacosta, O.; Lennon, L.; Whincup, P.H.; Sattar, N. Copeptin, Insulin Resistance, and Risk of Incident Diabetes in Older Men. J. Clin. Endocrinol. Metab. 2015, 100, 3332-3339. [CrossRef] [PubMed]

12. Johnson, E.C.; Bardis, C.N.; Jansen, L.T.; Adams, J.D.; Kirkland, T.W.; Kavouras, S.A. Reduced water intake deteriorates glucose regulation in patients with type 2 diabetes. Nutr. Res. 2017, 43, 25-32. [CrossRef]

13. Enhorning, S.; Struck, J.; Wirfalt, E.; Hedblad, B.; Morgenthaler, N.G.; Melander, O. Plasma copeptin, a unifying factor behind the metabolic syndrome. J. Clin. Endocrinol. Metab. 2011, 96, E1065-E1072. [CrossRef] [PubMed]

14. Tasevska, I.; Enhorning, S.; Persson, M.; Nilsson, P.M.; Melander, O. Copeptin predicts coronary artery disease cardiovascular and total mortality. Heart 2016, 102, 127-132. [CrossRef] [PubMed]

15. Melander, O. Vasopressin, from Regulator to Disease Predictor for Diabetes and Cardiometabolic Risk. Ann. Nutr. AMP Metab. 2016, 68 (Suppl. 2), 24-28. [CrossRef]

16. Enhorning, S.; Hedblad, B.; Nilsson, P.M.; Engstrom, G.; Melander, O. Copeptin is an independent predictor of diabetic heart disease and death. Am. Heart J. 2015, 169, 549-556. [CrossRef] [PubMed]

17. Riphagen, I.J.; Boertien, W.E.; Alkhalaf, A.; Kleefstra, N.; Gansevoort, R.T.; Groenier, K.H.; van Hateren, K.J.; Struck, J.; Navis, G.; Bilo, H.J.; et al. Copeptin, a surrogate marker for arginine vasopressin, is associated with cardiovascular and all-cause mortality in patients with type 2 diabetes (ZODIAC-31). Diabetes Care 2013, 36, 3201-3207. [CrossRef] [PubMed]

18. Chan, J.; Knutsen, S.F.; Blix, G.G.; Lee, J.W.; Fraser, G.E. Water, other fluids, and fatal coronary heart disease: The Adventist Health Study. Am. J. Epidemiol. 2002, 155, 827-833. [CrossRef]

19. Sontrop, J.M.; Dixon, S.N.; Garg, A.X.; Buendia-Jimenez, I.; Dohein, O.; Huang, S.H.; Clark, W.F. Association between water intake, chronic kidney disease, and cardiovascular disease: A cross-sectional analysis of NHANES data. Am. J. Nephrol. 2013, 37, 434-442. [CrossRef]

20. Clark, W.F.; Sontrop, J.M.; Huang, S.H.; Moist, L.; Bouby, N.; Bankir, L. Hydration and Chronic Kidney Disease Progression: A Critical Review of the Evidence. Am. J. Nephrol. 2016, 43, 281-292. [CrossRef] 
21. Clark, W.F.; Sontrop, J.M.; Huang, S.H.; Gallo, K.; Moist, L.; House, A.A.; Cuerden, M.S.; Weir, M.A.; Bagga, A.; Brimble, S.; et al. Effect of Coaching to Increase Water Intake on Kidney Function Decline in Adults With Chronic Kidney Disease: The CKD WIT Randomized Clinical Trial. JAMA 2018, 319, 1870-1879. [CrossRef]

22. Enhorning, S.; Christensson, A.; Melander, O. Plasma copeptin as a predictor of kidney disease. Nephrol. Dial. Transplant. 2019, 34, 74-82. [CrossRef] [PubMed]

23. Strippoli, G.F.; Craig, J.C.; Rochtchina, E.; Flood, V.M.; Wang, J.J.; Mitchell, P. Fluid and nutrient intake and risk of chronic kidney disease. Nephrology 2011, 16, 326-334. [CrossRef] [PubMed]

24. Sagar, P.S.; Zhang, J.; Luciuk, M.; Mannix, C.; Wong, A.T.Y.; Rangan, G.K. Increased water intake reduces long-term renal and cardiovascular disease progression in experimental polycystic kidney disease. PLOS ONE 2019, 14, e0209186. [CrossRef] [PubMed]

25. Wang, X.; Wu, Y.; Ward, C.J.; Harris, P.C.; Torres, V.E. Vasopressin directly regulates cyst growth in polycystic kidney disease. J. Am. Soc. Nephrol. JASN 2008, 19, 102-108. [CrossRef] [PubMed]

26. Torres, V.E.; Bankir, L.; Grantham, J.J. A case for water in the treatment of polycystic kidney disease. Clin. J. Am. Soc. Nephrol. CJASN 2009, 4, 1140-1150. [CrossRef] [PubMed]

27. Jiang, X.; Castelao, J.E.; Groshen, S.; Cortessis, V.K.; Shibata, D.K.; Conti, D.V.; Gago-Dominguez, M. Water intake and bladder cancer risk in Los Angeles County. Int. J. Cancer 2008, 123, 1649-1656. [CrossRef]

28. Braver, D.J.; Modan, M.; Chetrit, A.; Lusky, A.; Braf, Z. Drinking, micturition habits, and urine concentration as potential risk factors in urinary bladder cancer. J. Natl. Cancer Inst. 1987, 78, 437-440. [PubMed]

29. Villanueva, C.M.; Cantor, K.P.; King, W.D.; Jaakkola, J.J.; Cordier, S.; Lynch, C.F.; Porru, S.; Kogevinas, M. Total and specific fluid consumption as determinants of bladder cancer risk. Int. J. Cancer 2006, 118, 2040-2047. [CrossRef] [PubMed]

30. Cheuvront, S.N.; Ely, B.R.; Kenefick, R.W.; Sawka, M.N. Biological variation and diagnostic accuracy of dehydration assessment markers. Am. J. Clin. Nutr. 2010, 92, 565-573. [CrossRef]

31. Cheuvront, S.N.; Kenefick, R.W.; Charkoudian, N.; Sawka, M.N. Physiologic basis for understanding quantitative dehydration assessment. Am. J. Clin. Nutr. 2013, 97, 455-462. [CrossRef] [PubMed]

32. Armstrong, L.E.; Johnson, E.C.; Munoz, C.X.; Swokla, B.; Le Bellego, L.; Jimenez, L.; Casa, D.J.; Maresh, C.M. Hydration biomarkers and dietary fluid consumption of women. J. Acad. Nutr. Diet. 2012, 112, 1056-1061. [CrossRef] [PubMed]

33. Armstrong, L.E.; Pumerantz, A.C.; Fiala, K.A.; Roti, M.W.; Kavouras, S.A.; Casa, D.J.; Maresh, C.M. Human hydration indices: Acute and longitudinal reference values. Int. J. Sport Nutr. Exerc. Metab. 2010, 20, 145-153. [CrossRef] [PubMed]

34. Johnson, E.C.; Munoz, C.X.; Le Bellego, L.; Klein, A.; Casa, D.J.; Maresh, C.M.; Armstrong, L.E. Markers of the hydration process during fluid volume modification in women with habitual high or low daily fluid intakes. Eur. J. Appl. Physiol. 2015, 115, 1067-1074. [CrossRef] [PubMed]

35. Munoz, C.X.; Johnson, E.C.; McKenzie, A.L.; Guelinckx, I.; Graverholt, G.; Casa, D.J.; Maresh, C.M.; Armstrong, L.E. Habitual total water intake and dimensions of mood in healthy young women. Appetite 2015, 92, 81-86. [CrossRef] [PubMed]

36. Pross, N.; Demazieres, A.; Girard, N.; Barnouin, R.; Metzger, D.; Klein, A.; Perrier, E.; Guelinckx, I. Effects of changes in water intake on mood of high and low drinkers. PLoS ONE 2014, 9, e94754. [CrossRef] [PubMed]

37. Perrier, E.; Vergne, S.; Klein, A.; Poupin, M.; Rondeau, P.; Le Bellego, L.; Armstrong, L.E.; Lang, F.; Stookey, J.; Tack, I. Hydration biomarkers in free-living adults with different levels of habitual fluid consumption. Br. J. Nutr. 2013, 109, 1678-1687. [CrossRef] [PubMed]

38. Perrier, E.; Demazieres, A.; Girard, N.; Pross, N.; Osbild, D.; Metzger, D.; Guelinckx, I.; Klein, A. Circadian variation and responsiveness of hydration biomarkers to changes in daily water intake. Eur. J. Appl. Physiol. 2013, 113, 2143-2151. [CrossRef]

39. Wagenmakers, E.J. A practical solution to the pervasive problems of p values. Psychon. Bull. AMP Rev. 2007, 14, 779-804. [CrossRef]

40. Farrar, D.E.; Glauber, R.R. Multicollinearity in Regression Analysis: The Problem Revisited. Rev. Econ. Stat. 1967, 49, 92-107. [CrossRef]

41. Belsley, D.A. Conditioning Diagnostics: Collinearity and Weak Data in Regression; Wiley: New York, NY, USA, 1991.

42. Bollen, K.A. Structural Equations with Latent Variables; Wiley: New York, NY, USA, 1989. 
43. Hart, R.A.; MacKay, D.I. Wage Inflation, Regional Policy and the Regional Earnings Structure. Economica 1977, 44, 267-281. [CrossRef]

44. Browne, M.W.; Cudeck, R. Alternative ways of assessing model fit. Sociol. Methods Res. 1992, 21, $230-258$. [CrossRef]

45. Moore, G.P.; Perkel, D.H.; Segundo, J.P. Statistical analysis and functional interpretation of neuronal spike data. Annu. Rev. Physiol. 1966, 28, 493-522. [CrossRef] [PubMed]

46. Jaeger, B.C.; Edwards, L.J.; Das, K.; Sen, P. An $\mathrm{R}^{2}$ statistic for fixed effects in the generalized linear mixed model. J. Appl. Stat. 2017, 44, 1086-1105. [CrossRef]

47. Jacobson, M.H.; Levy, S.E.; Kaufman, R.M.; Gallinek, W.E.; Donnelly, O.W. Urine osmolality. A definitive test of renal function. Arch. Intern. Med. 1962, 110, 83-89. [CrossRef]

48. Armstrong, L.E. Assessing hydration status: The elusive gold standard. J. Am. Coll. Nutr. 2007, 26, 575s-584s. [CrossRef]

49. Munoz, C.X.; Johnson, E.C.; Demartini, J.K.; Huggins, R.A.; McKenzie, A.L.; Casa, D.J.; Maresh, C.M.; Armstrong, L.E. Assessment of hydration biomarkers including salivary osmolality during passive and active dehydration. Eur. J. Clin. Nutr. 2013, 67, 1257-1263. [CrossRef]

50. Perrier, E.; Rondeau, P.; Poupin, M.; Le Bellego, L.; Armstrong, L.E.; Lang, F.; Stookey, J.; Tack, I.; Vergne, S.; Klein, A. Relation between urinary hydration biomarkers and total fluid intake in healthy adults. Eur. J. Clin. Nutr. 2013, 67, 939-943. [CrossRef]

51. Perrier, E.T.; Buendia-Jimenez, I.; Vecchio, M.; Armstrong, L.E.; Tack, I.; Klein, A. Twenty-four-hour urine osmolality as a physiological index of adequate water intake. Dis. Mark. 2015, 2015, 231063. [CrossRef]

52. Cheuvront, S.N.; Kenefick, R.W.; Zambraski, E.J. Spot Urine Concentrations Should Not be Used for Hydration Assessment: A Methodology Review. Int. J. Sport Nutr. Exerc. Metab. 2015, 25, 293-297. [CrossRef]

53. Cheuvront, S.N.; Munoz, C.X.; Kenefick, R.W. The void in using urine concentration to assess population fluid intake adequacy or hydration status. Am. J. Clin. Nutr. 2016, 104, 553-556. [CrossRef] [PubMed]

54. Lemetais, G.; Melander, O.; Vecchio, M.; Bottin, J.H.; Enhorning, S.; Perrier, E.T. Effect of increased water intake on plasma copeptin in healthy adults. Eur. J. Nutr. 2018, 57, 1883-1890. [CrossRef] [PubMed]

55. Morgenthaler, N.G.; Struck, J.; Alonso, C.; Bergmann, A. Assay for the measurement of copeptin, a stable peptide derived from the precursor of vasopressin. Clin. Chem. 2006, 52, 112-119. [CrossRef] [PubMed]

56. Szinnai, G.; Morgenthaler, N.G.; Berneis, K.; Struck, J.; Muller, B.; Keller, U.; Christ-Crain, M. Changes in plasma copeptin, the c-terminal portion of arginine vasopressin during water deprivation and excess in healthy subjects. J. Clin. Endocrinol. Metab. 2007, 92, 3973-3978. [CrossRef] [PubMed]

57. Sun, Z.; Tao, Y.; Li, S.; Ferguson, K.K.; Meeker, J.D.; Park, S.K.; Batterman, S.A.; Mukherjee, B. Statistical strategies for constructing health risk models with multiple pollutants and their interactions: Possible choices and comparisons. Environ. Health Glob. Access. Sci. Sour. 2013, 12, 85. [CrossRef] [PubMed]

58. Schleicher, R.L.; McCoy, L.F.; Powers, C.D.; Sternberg, M.R.; Pfeiffer, C.M. Serum concentrations of an aflatoxin-albumin adduct in the National Health and Nutrition Examination Survey (NHANES) 1999-2000. Clin. Chim. Acta Int. J. Clin. Chem. 2013, 423, 46-50. [CrossRef] [PubMed]

59. United States Environmental Protection Agency (USEPA). Handbook for Use of Data from the National Health and Nutrition Examination Surveys (NHANES): A Goldmine of Data for Environmental Health Analyses; United States Environmental Protection Agency (USEPA): Washington, DC, USA, 2003.

60. CDC/National Center for Health Statistics. National Health and Nutrition Examination Survey. In Questionnaires, Datasets, and Related Documentation; CDC/National Center for Health Statistics: Hyattsville, MD, USA.

61. Malisova, O.; Bountziouka, V.; Panagiotakos, D.; Zampelas, A.; Kapsokefalou, M. Evaluation of seasonality on total water intake, water loss and water balance in the general population in Greece. J. Hum. Nutr. Diet. 2013, 26 (Suppl. 1), 90-96. [CrossRef]

62. McKenzie, A.L.; Perrier, E.T.; Guelinckx, I.; Kavouras, S.A.; Aerni, G.; Lee, E.C.; Volek, J.S.; Maresh, C.M.; Armstrong, L.E. Relationships between hydration biomarkers and total fluid intake in pregnant and lactating women. Eur. J. Nutr. 2017, 56, 2161-2170. [CrossRef]

63. Bougatsas, D.; Arnaoutis, G.; Panagiotakos, D.B.; Seal, A.D.; Johnson, E.C.; Bottin, J.H.; Tsipouridi, S.; Kavouras, S.A. Fluid consumption pattern and hydration among 8-14 years-old children. Eur. J. Clin. Nutr. 2017, 72, 420-427. [CrossRef] 
64. Peacock, O.J.; Stokes, K.; Thompson, D. Initial hydration status, fluid balance, and psychological affect during recreational exercise in adults. J. Sports Sci. 2011, 29, 897-904. [CrossRef]

65. Bland, J.M.; Altman, D.G. Statistical methods for assessing agreement between two methods of clinical measurement. Lancet 1986, 1, 307-310. [CrossRef]

66. Heller, K.E.; Sohn, W.; Burt, B.A.; Eklund, S.A. Water consumption in the United States in $1994-96$ and implications for water fluoridation policy. J. Public Health Dent. 1999, 59, 3-11. [CrossRef] [PubMed]

67. Wallis, K.F. Seasonal Adjustment and Relations between Variables. J. Am. Stat. Assoc. 1974, 69, $18-31$. [CrossRef]

68. Fahrni, T.K.M.; Sommer, P.; Wattenhofer, R.; Welten, S. Sundroid: Solar radiation awareness with smartphones. In Proceedings of the 13th International Conference on Ubiquitous Computing, Beijing, China, 17-21 September 2011; pp. 365-374.

69. Kinkeldei, T.Z.C.; Cherenack, K.H.; Troster, G. A textile integrated system for monitoring humidity and tempterature. In Proceedings of the IEEE 16th International Solid-State Sensors, Actuators and Microsystems Conference, Beijing, China, 5-9 June 2011; pp. 1156-1159.

70. Yun, J.K.J. Deployment Support for Sensor Networks in Indoor Climate Monitoring. Int. J. Distrib. Sens. Netw. 2013, 9, 875802. [CrossRef]

71. Yamamoto, Y.; Harada, S.; Yamamoto, D.; Honda, W.; Arie, T.; Akita, S.; Takei, K. Printed multifunctional flexible device with an integrated motion sensor for health care monitoring. Sci. Adv. 2016, 2, e1601473. [CrossRef] [PubMed]

72. Feng, J.C.Z.; He, C.; Li, Y.; Ye, X. Development of an improved wearable device for core body temperature monitoring based on the dual heat flux principle. Physiol. Meas. 2017, 38, 652-668. [CrossRef]

73. Atallah, L.C.C.; Wang, C.; Bongers, E.; Blom, T.; Paulussen, I.; Noordergraaf, G. An ergonomic wearable core body temperature sensor. In Proceedings of the IEEE 15th International Conference on Wearable and Implantable Body Sensor Networks, Las Vegas, NV, USA, 4-7 March 2018.

74. Nyein, H.Y.Y.; Tai, L.C.; Ngo, Q.P.; Chao, M.; Zhang, G.B.; Gao, W.; Bariya, M.; Bullock, J.; Kim, H.; Fahad, H.M.; et al. A Wearable Microfluidic Sensing Patch for Dynamic Sweat Secretion Analysis. ACS Sens. 2018, 3, 944-952. [CrossRef]

75. Wininger, M.; Bjornson, K. Filtering for productive activity changes outcomes in step-based monitoring among children. Physiol. Meas. 2016, 37, 2231-2244. [CrossRef]

76. Hoyt, W.T.; Imel, Z.E.; Chan, F. Multiple regression and correlation techniques: Recent controversies and best practices. Rehabil. Psychol. 2008, 53, 321-339. [CrossRef]

77. Osborne, J.W. Best Practices in Logistical Regression, 1st ed.; SAGE Publications, Inc.: Thousand Oaks, CA, USA, 2015.

78. Osborne, J. Best Practices in Quantitative Methods; SAGE Publications Ltd.: Thousand Oaks, CA, USA, 2008. 